

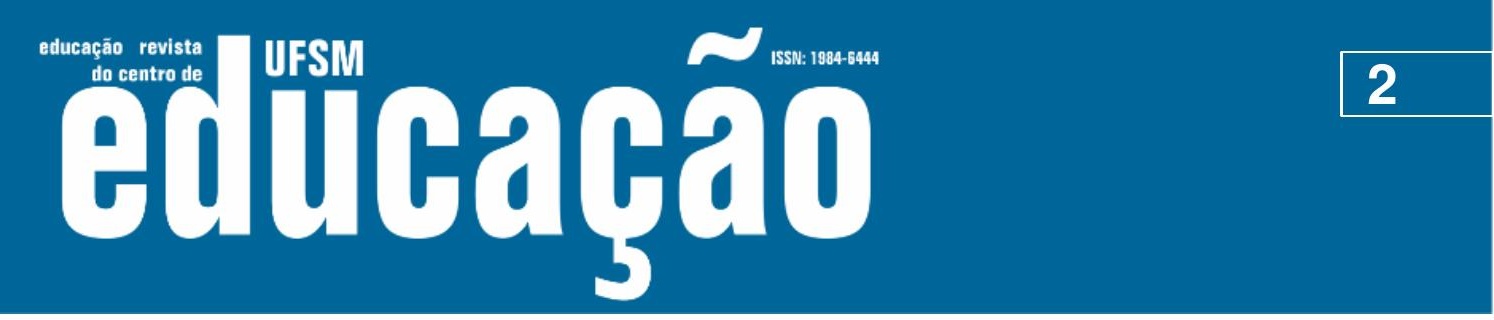

ISSN: 1984-6444 | http://dx.doi.org/10.5902/1984644461383

\section{ABSTRACT}

The purpose of this essay is to weave relations between curriculum and administration within the school, based on the consideration of its relations with the educational policy plan in which it is contextualized. The public school is assumed as the protagonist of the recontextualization of public policies and capable, therefore, of building genuinely democratic relations between curriculum and administration. It is considered that the curriculum in action with a view to human emancipation is directly linked to the concepts of democracy and culture, from the perspective of interculturality. The administrative / managerial function is understood both in the dimension concerning school administration itself and in the pedagogical dimension, since the primary purpose of the school, the reason its existence, is students' learning, which endows it of peculiar nature, purpose and special organizational criteria. Such criteria need to be established in accordance with the characteristics of the work developed in it, that is, the pedagogical work. Considering that the latter is within the scope of the curriculum, the inevitable existence of its relations with the administration/management is evidenced, and constitutes the idea defended and theoretically referenced in this text.

Keywords: Curriculum; School administration; Democracy.

\section{Introdução}

O tema das relações entre currículo e gestão tem sido alvo de escassa produção acadêmica, não obstante a relevância de sua consideração, conforme defendemos neste trabalho. De um levantamento de artigos por nós empreendido em três bases de dados brasileiras ${ }^{1}$ - SciELO, Capes Periódicos e Google Acadêmico - com emprego de termos de busca relacionados a este tema resultou 0 total de 29 artigos que o abordam diretamente. Este número corresponde a 6,8\% dos 428 artigos encontrados na primeira fase do levantamento.

Quanto ao tipo de trabalho, dos 29 diretamente vinculados ao tema em epígrafe 15 são bibliográficos, 11 se autoclassificam como qualitativos, dois como quantitativos e um como quanti-qualitativo. Já com relação ao objeto, predominam os artigos que abordam o tema do ponto de vista das políticas educacionais e/ou sociais $(48,3 \%)$. Apenas cinco artigos $(17,2 \%)$ focalizam a relação entre currículo e gestão no interior da escola, porém nenhum a considera na perspectiva do currículo em ação como fazemos neste texto. 


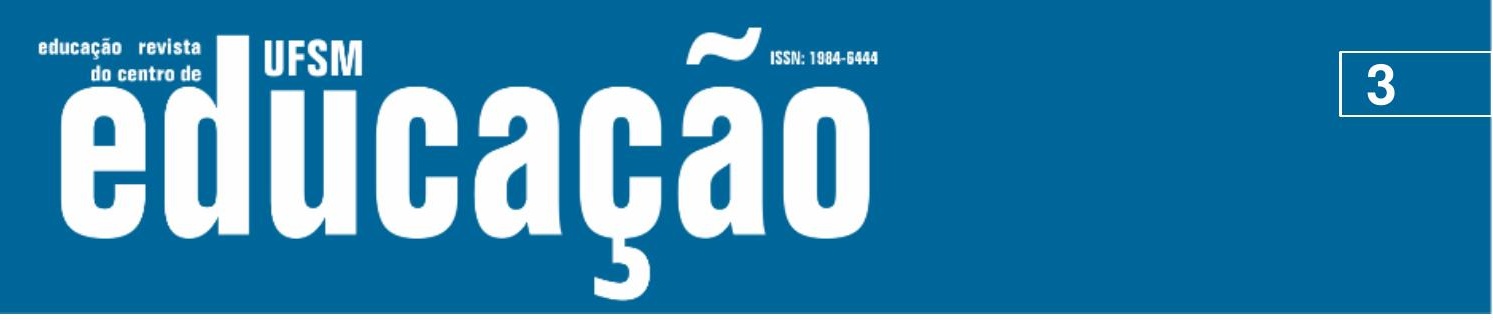

ISSN: 1984-6444 | http://dx.doi.org/10.5902/1984644461383

Ele se configura como um ensaio, isto é, como "uma primeira tentativa de sistematização de ideias sobre um assunto pouco explorado" (SALVADOR, 1982, p. 34). Seu objetivo é tecer relações entre currículo e gestão no âmbito da escola, sem desconsiderar o plano maior da política educacional em que se insere. Defende-se a escola pública como protagonista da recontextualização de políticas públicas e capaz, portanto, de construir relações genuinamente democráticas entre currículo e gestão.

O texto está estruturado em três seções. A primeira versa sobre as relações entre regulação e autonomia da escola pública; a segunda analisa possibilidades de construção do currículo na perspectiva da autonomia construída (BARROSO, 1996); e a terceira tece relações entre o currículo assim entendido e a gestão escolar.

\section{A escola pública entre a regulação e a autonomia}

Tomar o âmbito escolar como unidade analítica obriga a considerar suas relações com o plano da política educacional em que se insere, já que, de forma alguma, se supõe sua independência nem a autonomia total de sua estrutura e funcionamento em relação ao sistema de ensino em seus diferentes âmbitos.

A política educacional resulta "de disputas em que os grupos organizados tentam legitimar como universais, acima de particularismos, seus próprios interesses" (OLIVEIRA, 2010, p. 2). Por tais motivos, ela traz consigo importantes contradições, mais ou menos nítidas dependendo do momento histórico. Assim é que podemos notar, ao longo do tempo, a ressignificação dos conceitos, por exemplo, de justiça social e de igualdade, finalidades principais das políticas educacionais emanadas do Estado laico, republicano. Até as últimas décadas do Século XX prevaleceram os critérios de justiça social assentados nos princípios de redistribuição econômica, mobilidade social, meritocracia. Depois desse período, a política educacional se viu envolta numa crise de orientação decorrente da perda de consenso em relação a esses princípios. Isso se deveu, em parte, ao fracasso escolar das crianças e jovens originários dos meios populares e das novas exigências postas pelos movimentos sociais feministas, étnico-raciais, de pessoas 


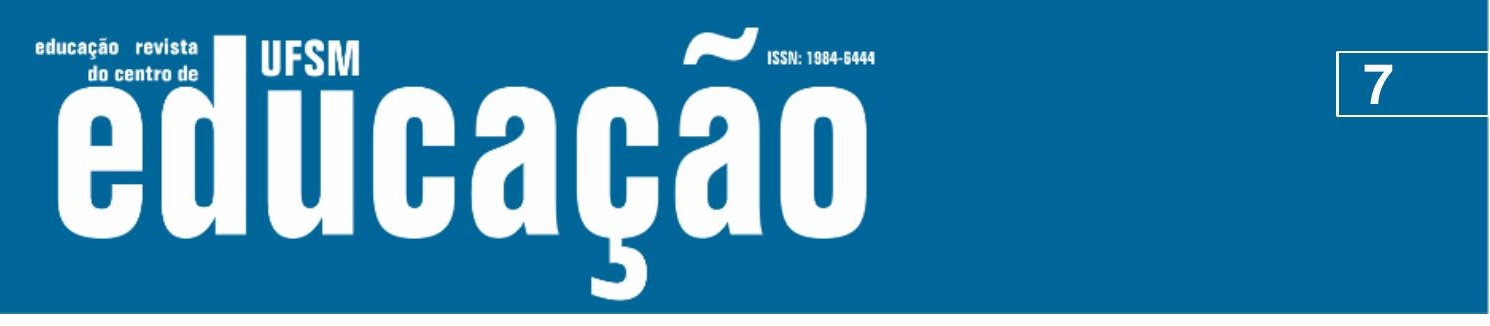

ISSN: 1984-6444 | http://dx.doi.org/10.5902/1984644461383

\begin{abstract}
A escola [...] não se reduz 'a um mero reverso das políticas', mas antes se configura como um espaço de reconstrução e de inovação, oferecendo elementos para a formulação de novas políticas: ao superar a crença de que o sentido das políticas reside unicamente no conteúdo das propostas governamentais, a significação e as relações de poder desvanecem-se através de uma trama de numerosos dispositivos e interações. Esta teia constitui o terreno no qual se cruzam os caminhos da inovação, caracterizados como um processo de construção social que abandona a polaridade essencialista entre governo e escolas.
\end{abstract}

Apostando nas possibilidades da autonomia - ainda que relativa - das escolas, passamos a analisar as relações entre autonomia e currículo.

\title{
A autonomia construída e o currículo
}

Como Silva Jr. (2015, p. 131), entendemos currículo como "o grande meio de realização da finalidade da escola". Cabe, então, perguntar que finalidade é essa, e se numa sociedade conservadora e neoliberal a escola estaria inexoravelmente fadada a servir à manutenção do status quo. Apple (2006, p. 13) assim formula essa pergunta, ao mesmo tempo em que a responde:

[...] é possível fazer algo diferente, que interrompa as políticas neoliberais e neoconservadoras, que tenha uma política muito diferente de conhecimento legítimo e seja baseado em um real compromisso de criar escolas intimamente relacionadas a um projeto maior de transformação social? Penso que sim.

Para isso, ele sinaliza a importância de conhecermos por dentro como se dá a engrenagem das "forças complexas que têm impacto em nossas escolas" (p. 15). $\mathrm{Na}$ mesma linha de pensamento, autores como Giroux (1986), Young (2007), McLaren (1997), entre outros, a par de compreenderem os mecanismos de dominação e poder que caracterizam a instituição escolar em sociedades capitalistas, não a encaram como uma engrenagem completamente determinada pelas relações de dominação, mas enxergam nela uma autonomia relativa, levando-os, portanto, à mesma resposta dada por Apple na citação anterior. Young (2007, p. 1292), por exemplo, assume que "até os sistemas escolares mais opressivos podem ser usados como instrumentos de emancipação", e ilustra esta asserção com o caso de 


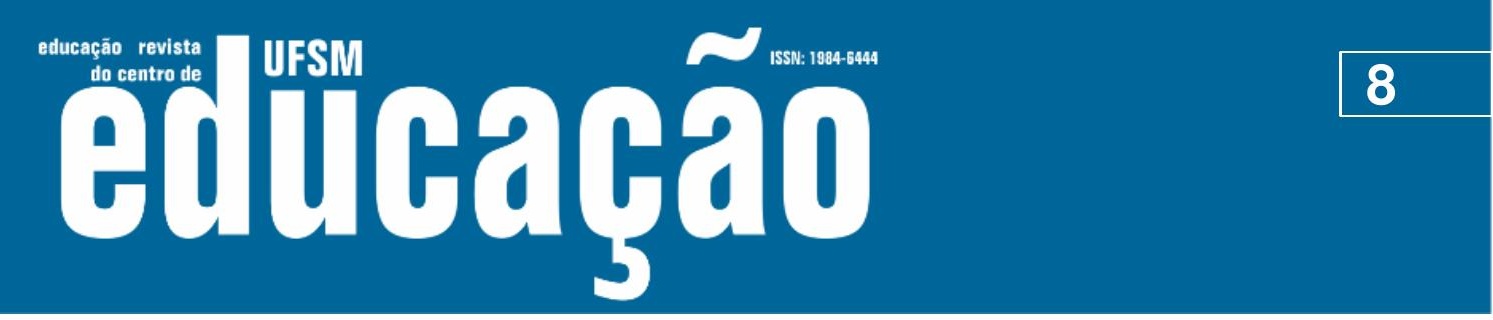

ISSN: 1984-6444 | http://dx.doi.org/10.5902/1984644461383

Nelson Mandela ter estudado em escolas para africanos anteriores à educação bantu.

Tal compreensão é compatível com a ideia de currículo como

[...] um processo de coordenação da acção dos atores no terreno que resulta do confronto, da interacção, da negociação ou do compromisso de diferentes interesses, lógicas, racionalidades e estratégias em presença, quer numa perspectiva vertical entre "administradores" e "administrados", quer numa perspectiva horizontal, entre os ocupantes de um diferente espaço de interdependência (intra e interorganizacional) - escolas, territórios educativos, municípios etc. (BARROSO, 2004, p. 24).

Esta visão se coaduna com as de regulação local (BARROSO, 2004), de autonomia construída (BARROSO,1996) e de currículo como processo construído no cotidiano da escola, com base em um projeto de educação consubstanciado em um texto curricular (GIMENO SACRISTÁN, 2013), que constitui o currículo oficial, primeiro dos cinco planos componentes do processo curricular. O segundo plano é o da interpretação que os docentes e os materiais curriculares fazem desse texto; 0 terceiro é o de sua colocação em prática com sujeitos concretos em um contexto determinado; o quarto plano é o dos efeitos produzidos nos estudantes e é, portanto, subjetivo; finalmente, o quinto é o do currículo avaliado, que em geral fica restrito aos resultados observáveis e mensuráveis, de modo a não se ter a real dimensão de seus efeitos nos estudantes, como adverte Gimeno Sacristán (2013).

Visto dessa forma, assume-se a importância do texto curricular - ou currículo preativo, currículo formal, ou ainda currículo escrito - uma vez que, de acordo com Goodson (1995, p. 20), "é politicamente ingênuo e conceitualmente inadequado afirmar que 'o importante é a prática em sala de aula' (da mesma forma que é uma ignorância querer excluir a política da educação)". Todavia, ao ser interpretado e colocado em prática é que o texto ganha vida e produz efeitos nos estudantes.

Reconhecemos estreita vinculação entre o conceito de currículo em ação, cunhado por Geraldi (1994) - e esse conjunto de ideias. Nesta acepção, 


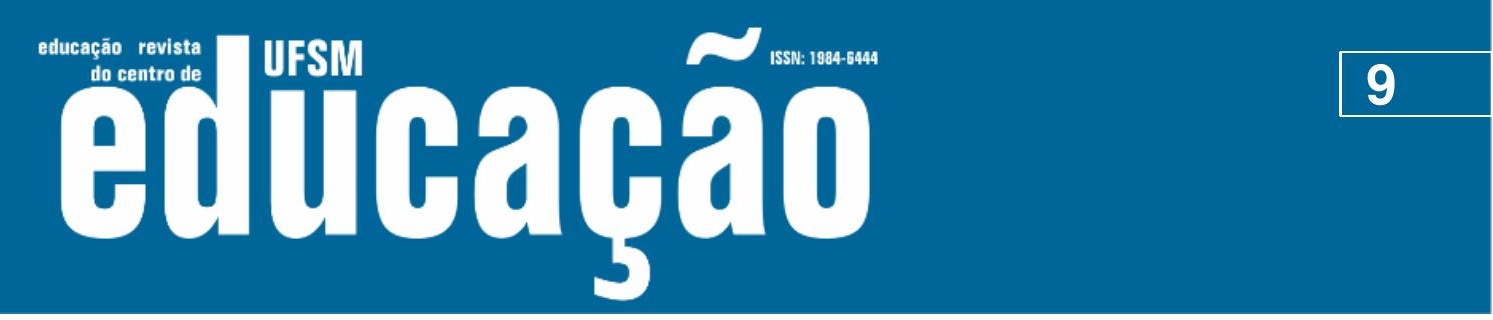

ISSN: 1984-6444 | http://dx.doi.org/10.5902/1984644461383

O currículo é entendido e trabalhado como o conjunto das aprendizagens vivenciadas pelos alunos, planejadas ou não pela escola, dentro e fora da sala de aula e da escola, mas sob a responsabilidade desta, ao longo de sua trajetória escolar (GERALDI, 1994, P. 117 - grifos da autora)

Assim como Geraldi (1994), defendemos que o currículo em ação, em estreita relação com o texto curricular, tenha interesse na emancipação humana, paradigma inaugurado no Brasil por Paulo Freire, no final da década de 1960, com seu protagonismo nos movimentos de alfabetização popular caracterizados pela conscientização política, e o consequente lançamento de sua obra seminal, "Pedagogia do oprimido" (FREIRE, 1970). A esse respeito, Geraldi (1994) lembra que devemos a Freire o primeiro esforço no Brasil em enfocar conhecimento e currículo com interesse em emancipação, o que significou rompimento com o paradigma técnico-linear. "Curiosamente", a obra teve reverberação espantosa no exterior, enquanto o velho paradigma sobrevivia no Brasil, fazendo coro à ditadura civil-militar vigente à época.

A nosso ver, o currículo em ação com vistas à emancipação vincula-se diretamente a dois conceitos-chave: a democracia e a cultura, na perspectiva da interculturalidade.

A democracia é concebida por Toro (1999, p. 2) não como liberalismo econômico, como laissez-faire econômico, como um partido, como uma religião, uma ciência, mas como "uma cosmovisão", isto é, "uma forma de ver o mundo". De acordo com o autor, a compreensão deste conceito pode transformar completamente a educação. Ele propõe seis princípios fundantes da democracia: a secularidade, a autofundação, a incerteza, a ética, a complexidade e o público.

Pelo princípio da secularidade entende-se que "toda ordem é construída. A ordem não é natural, por isso transformações na sociedade são possíveis" (p. 3). A democracia também não é natural; ela é um invento, uma criação e, como tal, é necessário ensiná-la e aprendê-la. Uma forma de transpor esse princípio para o currículo em ação é não naturalizar questões que de fato não são naturais, como, por exemplo, o fato de uns alunos aprenderem e outros não, e de justificar fatos como esses com respostas como: porque é assim, ou porque sempre foi assim. 


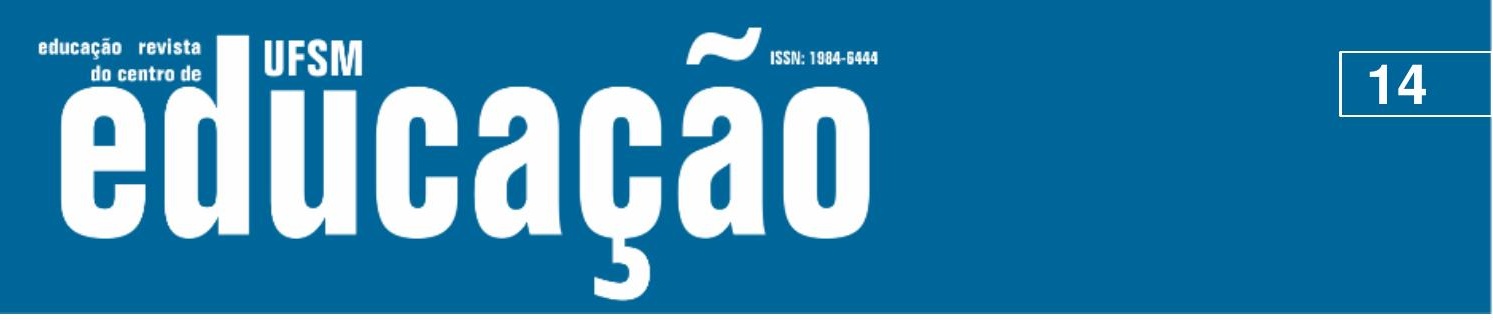

ISSN: 1984-6444 | http://dx.doi.org/10.5902/1984644461383

\begin{abstract}
De acordo com esse conceito mais abrangente de administração, a mediação a que se refere não se restringe às atividades-meio, porém perpassa todo o processo de busca de objetivos. Isso significa que não apenas direção, serviços de secretaria e demais atividades que dão subsídios e sustentação à atividade pedagógica da escola são de natureza administrativa, mas também a atividade pedagógica em si - pois a busca de fins não se restringe às atividades-meio, mas continua, de forma ainda mais intensa, nas atividades-fim (aquelas que envolvem diretamente o processo ensino-aprendizado) (PARO, 2010, p. 765).
\end{abstract}

Fica, então, entendido que a função administrativa/gestora da escola referindo-nos em específico à escola pública como local de trabalho (SILVA JR., 2015) - envolve, necessariamente, tanto a dimensão concernente à administração escolar propriamente dita quanto a dimensão pedagógica, visto que a razão de ser, ou o fim por excelência da escola é a educação de seus estudantes. Ela é, pois, dotada de finalidade e natureza peculiares e supõe critérios especiais de organização. Tais critérios precisam ser estabelecidos em conformidade com as caraterísticas do trabalho nela desenvolvido, ou seja, o trabalho pedagógico.

Considerando-se que o trabalho pedagógico desenvolvido na escola é da alçada do currículo fica, por via de consequência, evidenciada a inevitável existência de relações entre ele e a administração/gestão.

Para Pacheco (2011), currículo e gestão se conjugam de forma interdependente porque ambos são campos de ação políticos.

No plano político mais amplo, Thiesen (2014) explica que a inter-relação de currículo e gestão pode ser entendida no seio da contradição entre o Estado avaliador dos resultados dos processos educacionais pela via da estandardização e a manutenção do discurso da gestão democrática da educação pública. Trata-se, a nosso ver, de uma repaginação de lógicas tecnicistas em uma clara tendência conservadora, ou neoconservadora, de gestão dos currículos nas escolas ditadas pelos organismos internacionais voltados à educação. Esse conservadorismo pode se constituir em significativa ameaça à democracia, à inclusão e à justiça social, pois o compromisso da educação pública seria com a formação do sujeito produtivo e, principalmente, consumidor, que atenderia, dessa forma, às demandas do mercado e do consumo. 


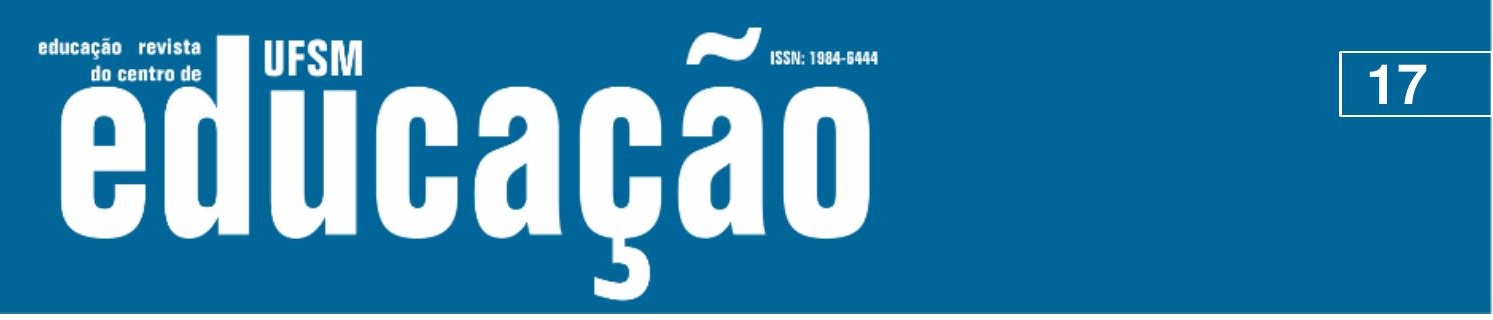

ISSN: 1984-6444 | http://dx.doi.org/10.5902/1984644461383

Nesse novo projeto social, compete à escola proporcionar aos estudantes novas formas de se pensar o mundo, o que passa necessariamente pela relação entre currículo e gestão pautada na interculturalidade, isto é, no respeito à diferença e na busca da igualdade de direitos. Entendemos a igualdade como oposta à desigualdade vista como inferioridade em comparação a um padrão, e a diferença como oposta à igualdade quando esta é vista como padronização.

Nos termos propostos, é necessário que a gestão escolar cumpra o papel de coordenar: a definição da política institucional relacionada ao currículo formal/prescrito; o acompanhamento do currículo em ação. A esse processo chamamos de "gestão em ação".

\section{Referências}

APPLE, Michael Whitman. Ideologia e currículo. 3ª ed. Porto Alegre: Artmed, 2006.

BARROSO, João. O estudo da autonomia da escola: da autonomia decretada à autonomia construída. In: BARROSO, João (org). O Estudo da Escola. Porto: Porto Editora, 1996, pp. 167-189.

BARROSO, João. Os novos modos de regulação das políticas educativas na Europa: da regulação do sistema a um sistema de regulações. Educação em Revista, Belo Horizonte, n. 39, p. 19-28, jul. 2004.

BARROSO, João. O Estado, a educação e a regulação das políticas públicas. Educação e Sociedade. Campinas, vol. 26, n. 92, p. 725-751, Especial - Out. 2005. Disponível em http://www.cedes.unicamp.br Acesso em: 26 abril, 2020.

BARROSO, João. A autonomia das escolas: retórica, instrumento e modo de regulação da acção política. In: AAVV. A autonomia das escolas. Lisboa: Fundação Calouste Gulbenkian, 2006. Disponível em https://www.researchgate.net/publication/237669078. Acesso em: 03 setembro, 2020.

CANDAU, Vera Maria. Revista Nuevamerica / Novamerica, n. 91, set. 2001. Entrevista.

FREIRE, Paulo. Pedagogia do oprimido. Rio de Janeiro: Paz e Terra, 1970.

GERALDI, Corinta Maria Grisolia. Currículo em ação: buscando a compreensão do cotidiano da escola básica. Pro-Posições, v. 5, n. 3[15], nov. 1994. 


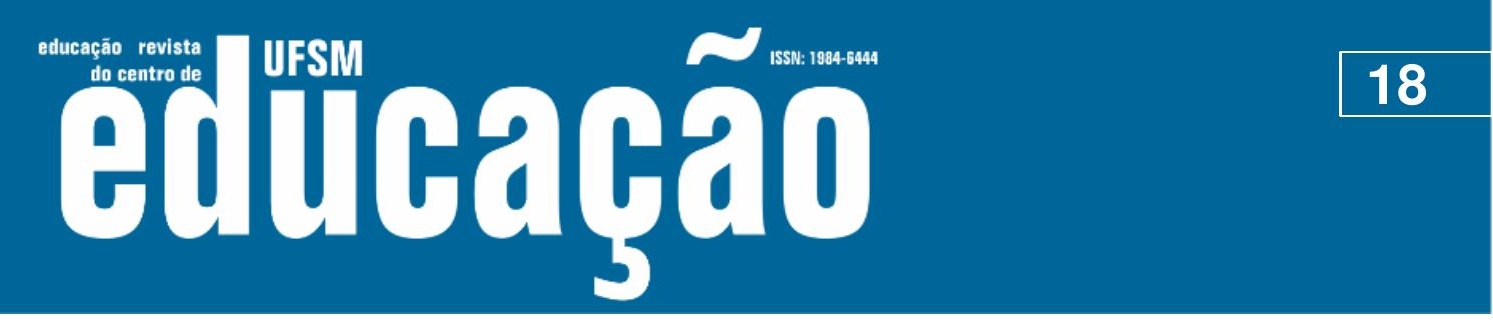

ISSN: 1984-6444 | http://dx.doi.org/10.5902/1984644461383

GIMENO SACRISTÁN, Jose. O que significa o currículo? In: GIMENO SACRISTÁN, J. (org.). Saberes e incertezas sobre o currículo. Porto Alegre: Penso, 2013.

GIROUX, Henry. Pedagogia Radical: subsídios. São Paulo: Cortez, 1983.

GIROUX, Henry. Para além das teorias da reprodução: teoria crítica e resistência em educação. Rio de Janeiro: Vozes, 1986.

GOODSON, Ivor Frederick. Currículo: teoria e história. $2^{\underline{a}}$ ed. Petrópolis: Vozes, 1995

HYPOLITO, Álvaro Luiz Moreira. Estado gerencial, reestruturação educativa e gestão escolar. Revista Brasileira de Política e Administração da Educação, Porto Alegre, v. 24, n. 1, p. 63-78, jan./abr. 2008.

HYPOLITO, Álvaro Luiz Moreira. Políticas curriculares, Estado e regulação. Educ. Soc., Campinas, v. 31, n. 113, p. 1337-1354, out-dez. 2010. Disponível em: http://www.cedes.unicamp.br Acesso: em 07 maio, 2020.

KRAWCZYK, Nora Rut. Políticas de regulação e mercantilização da educação: socialização para uma nova cidadania? Educação e Socieade, Campinas, vol. 26, n. 92, p. 799-819, Especial - Out. 2005.

LADSON-BILLINGS Gloria. Para além de uma educação multicultural: teoria racial crítica, pedagogia culturalmente relevante e formação docente. Educação e Sociedade, n. 79, 2002. Entrevista.

LIMA, Emília Freitas de. Apontamentos sobre ensino e formação de professores intermulticulturais Série-Estudos - Periódico do Mestrado em Educação da UCDB. Campo Grande-MS, n. 27, p. 65-81, jan./jun. 2009.

McLAREN, Peter. A vida nas escolas. Uma introdução à pedagogia crítica nos fundamentos da educação. 2ª ed. Porto Alegre, Artes Médicas, 1997.

MIGUEL, Luis Felipe. Teoria democrática atual: esboço de mapeamento. BIB Revista Brasileira de Informação Bibliográfica em Ciências Sociais, São Paulo, $\mathrm{n}^{\circ} \quad 59, \quad 1^{\circ} \quad$ semestre de 2005, pp. 5-42. Disponível em: http://www.anpocs.com/index.php/edicoes-anteriores/bib-59/569-teoria-democraticaatual-esboco-de-mapeamento/file. Acesso em 20 Abril, 2020.

MOREIRA, Antônio Flávio Barbosa. A recente produção científica sobre currículo e multiculturalismo no Brasil (1995-2000): avanços, desafios e tensões. Revista Brasileira de Educação, n. 18. set./out./nov./dez. 2001. 


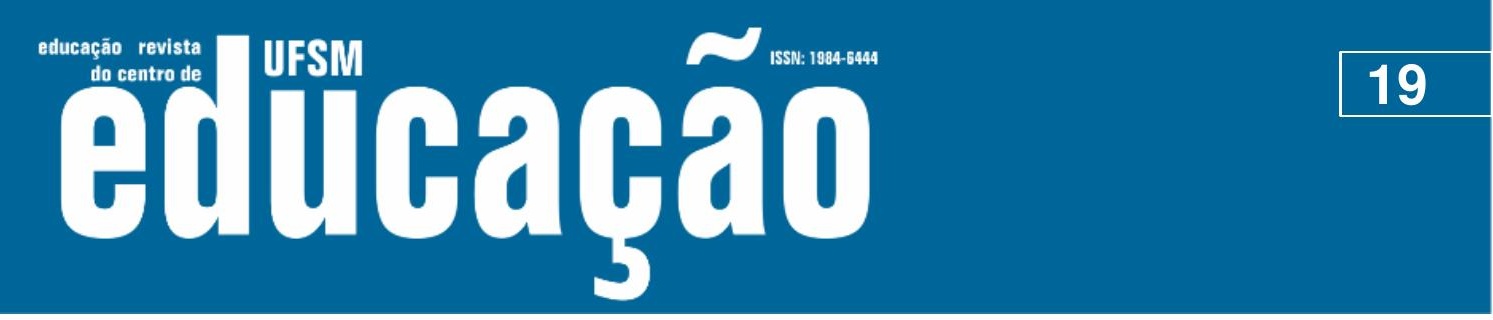

ISSN: 1984-6444 | http://dx.doi.org/10.5902/1984644461383

NÓVOA, António. Para uma análise das instituições escolares. In: NÓVOA, António. (org.). As organizações escolares em análise. $1^{\underline{a}}$ ed. Lisboa: Publicações Dom Quixote, 1992. P. 13-43.

OLIVEIRA, Dalila Andrade. Política educacional. In: OLIVEIRA, D.A.; DUARTE, A.M.C.; VIEIRA, L.M.F. Dicionário: trabalho, profissão e condição docente. Belo Horizonte: UFMG/Faculdade de Educação, 2010. CDROM

PACHECO, José Augusto. A. Currículo e gestão escolar no contexto das políticas educacionais. Revista Brasileira de Política e Administração da Educação, v.27, n.3, p. 377-390, set./dez. 2011.

PARO, Vitor Henrique. Situação e perspectivas da administração da educação brasileira: uma contribuição. Revista Brasileira de Administração da Educação. Brasília, v. 9, n. 1, p. 9-36, jan./jun. 1993.

PARO, Vitor Henrique. A educação, a política e a administração: reflexões sobre a prática do diretor de escola. Educação e Pesquisa, São Paulo, v. 36, n.3, p. 763778, set./dez. 2010

SALVADOR, Ângelo Domingos. Métodos e técnicas de pesquisa bibliográfica. 10aㅡ ed. rev. ampl. Porto Alegre: Sulina, 1982.

SILVA JR., Celestino Alves. Para uma teoria da escola pública no Brasil. Marília: M3T Edições e Treinamento, 2015.

THIESEN, Juares da Silva. Currículo e gestão escolar: territórios de autonomia colocados sob a mira dos standards educacionais. Currículo sem Fronteiras, v. 14, n. 1, p. 192-202, jan./abr. 2014.

TORO, José Bernardo. Educación para la democracia. CIVICUS/Funredes, Bogotá, 1999. Disponível em https://scholar.google.com/scholar? cluster= $6190629558671922318 \& \mathrm{hl}=\mathrm{pt} \quad$-BR\&as_sdt=2005\&sciodt=0,5. Acesso em 20.04.2020.

TUBINO, Fidel. Del interculturalismo funcional al interculturalismo crítico. Disponível em: https://red.pucp.edu.pe/ridei/wp-content /uploads /biblioteca /inter funcional.pdf. Acesso: 03 Set. 2020.

VIEIRA, Sofia Lerche. Política(s) e Gestão da Educação Básica: revisitando conceitos simples. Revista Brasileira de Política e Administração da Educação, v.23, n.1, p. 53-69, jan./abr. 2007.

WILLIAMS, Raymond. Cultura. 2ª ed. Rio de Janeiro: Paz e Terra, 2000. 


\section{$\sim$

ISSN: 1984-6444 | http://dx.doi.org/10.5902/1984644461383

YOUNG, Michael. Para que servem as escolas? Educação e Sociedade, Campinas, vol. 28, n. 101, p. 1287-1302, set./dez. 2007. Disponível em http://www.cedes.unicamp.br. Acesso em: 20 abril, 2020.

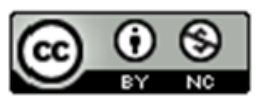

This work is licensed under a Creative Commons Attribution-NonCommercial 4.0 International (CC BY-NC 4.0)

\section{Notas}

1 O referido levantamento constitui parte de uma pesquisa em andamento, de nossa autoria, na qual os artigos sobre relações entre currículo e gestão serão analisados em um trabalho acadêmico específico.

2 BAUBY, P. L’Europe des services publics: entre libéralisation, modernisation, régulation, évaluation. Politique et Management Public, n. 1, p. 15, 2002.

3 MAROY, C.; DUPRIEZ, V. La régulation dans les systèmes scolaires: proposition théorique et analyse du cadre structurel en Belgique francophone. Revue Française de Pédagogie, Paris, n. 130, p. 73-87, jan/mar. 2000.

${ }^{4}$ COUTINHO, C.N. Cidadania, democracia e educação. Ideias, São Paulo, n. 24, p. 13-26, 1994.

5 GONZÁLEZ, Mạ . Teresa. Organización escolar e innovación educativa. In: La calidad de los centros educativos. Alicante: Sociedad Española de Pedagogía/IX Congreso Nacional de Pedagogía, 1988, pp. 179-199.

6 ALMANDOZ, Maria Rosa; VITAR, Ana. Caminhos da inovação: as políticas e as escolas. In: VITAR, Ana; ZIBAS, Dagmar; FERRETTI, Celso; TARTUCE, Gisela Lobo B. P. (Org.). Gestão de inovações no ensino médio: Argentina, Brasil, Espanha. Brasília: Líber Livro Editora, 2006. 